\title{
Efektivitas Model Discovery Learning dan Problem Based Learning terhadap Berpikir Kreatif dan Kemampuan Pemecahan Masalah Matematika
}

\author{
Ferawati $^{\left.1^{*}\right)}$, \& Huri Suhendri ${ }^{2}$ \\ ${ }^{1}$ STMIK Bina Sarana Global, Tangerang, Indonesia \\ ${ }^{2}$ Universitas Indraprasta PGRI, Jakarta, Indonesia
}

\begin{tabular}{l} 
INFO ARTICLES \\
\hline Article History: \\
Received: $23-12-2020$ \\
Revised: $24-12-2020$ \\
Approved: $24-12-2020$ \\
Publish Online: $25-12-2020$ \\
\hline
\end{tabular}

Key Words:

Cooperative Learning; Creative Thinking; Mathematical ProblemSolving Abilities;

\section{c) (7) (2)}

BY SA This article is licensed under a Creative Commons AttributionShareAlike 4.0 International License.

\begin{abstract}
This research aims to determine the effect of discovery learning model and problem-based learning model in creative thinking and mathematical problem-solving abilities. This research uses a quasiexperimental technique. The affordable population in this study is SMK Bina Mandiri and SMK Bina Karya with a sample of 80 students. Data are analysed using Post-test-Only-Design with multivariate analysis of variance (MANOVA). The result shows that there is a significant influence on discovery learning model and problem-based learning model in creative thinking and mathematical problem-solving abilities.
\end{abstract}

\begin{abstract}
Abstrak: Penelitian ini bertujuan untuk mengetahui pengaruh penggunaan model discovery learning dan problem based learning terhadap berpikir kreatif dan kemampuan pemecahan masalah matematika. Penelitian ini menggunakan teknik kuasi eksperimen. Populasi terjangkau dalam penelitian ini SMK Bina Mandiri dan SMK Bina Karya dan sampel sebanyak 80 siswa. Data dianalisis menggunakan Posttest-Only-Design dengan Multivariate Analysis of Variance (MANOVA). Hasil menunjukkan bahwa model discovery learning dan problem based learning efektif untuk meningkatkan berpikir kreatif dan kemampuan pemecahan masalah matematika.
\end{abstract}

\footnotetext{
Correspondence Address: J1. Aria Santika No. 43A Margasari, Kecamatan Karawaci, Kota Tangerang, Banten, 15114, Indonesia; -mail: ferawati@stmikglobal.ac.id

How to Cite (APA $6^{\text {th }}$ Style): Ferawati, F., \& Suhendri, H. (2020). Efektivitas Model Discovery Learning dan Problem Based Learning terhadap Berpikir Kreatif dan Kemampuan Pemecahan Masalah Matematika. JKPM (Jurnal Kajian Pendidikan Matematika), 6(1): 111-120.

Copyright: 2020 Ferawati Ferawati, Huri Suhendri

Competing Interests Disclosures: The authors declare that they have no significant competing financial, professional or personal interests that might have influenced the performance or presentation of the work described in this manuscript.
} 


\section{PENDAHULUAN}

Matematika tidak hanya bidang ilmu dalam dunia pendidikan tetapi juga bidang studi atau mata pelajaran yang dibutuhkan karena peranannya yang sangat penting untuk siswa, guru dan para penggiat bidang kelimuan lainnya. Oleh karena itu kedudukan matematika dalam dunia pendidikan sangat besar pengaruhnya dan menjadikan matematika mata pelajaran wajib di setiap jenjang pendidikan. Sesuai dengan pendapat Orton dan Frobisher (2009:1) mathematic is extensively appreared as one of the vital topic withinside the college curriculum. Matematika dianggap sebagai topik yang paling penting dalam kurikulum sekolah.

Dalam mempelajari matematika seseorang tidak tidak terlepas dari masalah karena keberhasilan seseorang dalam belajar matematika ditandai dengan kemampuan dalam menyelesaikan masalah yang sedang dihadapinya. Tuntutan kurikulum memaparkan betapa pentingnya kemampuan siswa dalam menyelesaikan masalah (Andriani, 2016 :85).

Matematika berkaitan dengan simbol-simbol karena sifatnya yang abstrak serta tersusun dengan sistematis serta penalaran deduktif sehingga konsep yang ada di matematika harus dipahami dan dikuasai afar dapat memanipulasi simbol tersebut. Matematika secara teratur tersusun dengan urutan yang logis (hirarkis) yang mengartikan bahwa suatu topik yang ada merupakan sebuah prasyarat untuk topik berikutnya. Dengan mempelajari suatu topik yang ada dalam matematika seseorang kan memperoleh pengalaman belajar yang akan mempengaruhi prosesnya dalam mempelajari dan cara berpikir matematika. Masalah yang dihadapi saat ini pada proses pembelajaran matematika yaitu kemampuan yang rendah dalam penyelesaian soal dalam bentuk cerita yang lebih menekankan berpikir kreatif dalam suatu pokok materi serta penyelesaian dengan pemecahan masalah.

Siswa seringkali mengalami kesulitan untuk memahami matematika karena matematika memiliki sifat yang salah satunya adalah abstrak karena itu membutuhkan penalaran yang cukup tinggi dalam memahami konsep disetiap materi pokok matematika. Oleh sebab itu untuk mempermudah siswa memahami matematika peru diterapkannya model pembelajaran yang tidak monoton dan dapat membantu siswa dalam penguasaan matematika sedini mungkin dari tingkat sekolah dasar. Namun pengaran yang baik tidak cukup hanya dengan siswa memperoleh hasil belajar yang sudah mencukupi ketuntasan belajar, karena masalah ynag dihadapi oleh guru ketika proses pembelajaran berlangsung yaitu untuk menumbuhkan berpikir kreatif serta kemampuan pemecahan masalah matematika. Dalam hal ini banyak guru mengajarkan dengan metode konvensional yang hanya memberikan soal latihan sesuai dengan contoh yang diberikan. Hal ini yang dapat membuat siswa kurang dalam melatih dirinya dalam berpikir kreatif dalam mengerjakan soal dan memecahkan masalah.

Berpikir kreatif dapat menghasilkan ide yang baru yang diperoleh dari berbagai macam pemikiran. Hal ini sependapat dengan Sari (2016: 5) bahwa berpikir kreatif jika seseorang dapat menemukan beberapa ide baru namun ide baru yang ditemukan seseorang adalah suatu gabungan yang dimiliki sebelumnya namun belum dikemukakan. Prasetyo (2016: 451) menyatakan bahwa aspek pada berpikir kreatif yaitu kelancaran, keluwesan, keaslian, dan keterincian.

Berpikir kreatif setiap siswa dapat dikembangkan dengan pemecahan masalah. Dengan adanya kemampuan pemecahan masalah siswa akan berpikir secara logis dan kritis dalam mendapatkan solusisolusi dari setiap permasalahan yang ada. Hal ini juga dapat dikatakan seperti pendapat Maimunah, Purwanto, Sa'dijah, \& Sisworo (2016) kemampuan pemecahan masalah merupakan kegiatan intelektual yang berguna untuk menemukan solusi dari setiap permasalahan dengan melibatkan pengalaman dan pengetahuan. Maka dengan memecahkan masalah, siswa akan berusaha menemukan solusi-solusi yang tepat dengan caranya agar dapat menyelesaikan setiap permasalahan yang dihadapi. 
Keberhasilan belajar mengajar dipengaruhi oleh banyak faktor yaitu kemampuan dasar siswa, kemampuan guru dalam menjelaskan, model pembelajaran, sarana prasarana maupun kreativitas siswa, karena semua memiiki kaitan dalam mencapai keberhasilan hasil belajar siswa. Walaupun tujuan pembelajaran sudah dirumuskan dengan baik, namun jika pemilihan model pembelajaran kurang memadai maka tujuan pembelajaran yang diharapkan dicapai tidak sesuai dengan keinginan yang diharapkan. Sehingga model pembelajaran merupakan bagian komponen yang penting untuk mencapai tujuan pembelajaran agar hasil belajar siswa dapat tercapai.

Guru harus memperhatikan dalam menyajikan materi, hendaknya pada proses pembelajaran guru harus memilih serta pendekatan metode maupun teknik yang digunakan mampu melibatkan siswa menjadi aktif saat proses pembeajaran berlangsung. Pembelajaran dapat dijadikan cara guru dalam mengajar untuk menjadikan siswa aktif dalam proses pembelajaran. Dalam penelitian ini penulis menggunakan penerapan model pembelajaran discovery learning dan problem based learning. Hosnan (2014: 282) mengatakan discovery learning merupakan model pembelajaran yang bertujuan untuk meningkatkan siswa menjadi aktif karena siswa dituntuk untuk menemukan dan menyelidiki agar hasil yang diperoleh akan selalu diingat. Model discovery learning dapat memotivasi siswa untuk belajar dan memberi kesempatan sesuai dengan kemampuan serta mengarahkan cara belajar masing-masing sehingga siswa merasa terlibat secara langsung dalam proses pembelajaran (Marantika, 2015). Langkah-langkah discovery learning (Nafisa, 2019) yaitu stimulus, problem statement, pengumpulan data, pengolahan data, pembuktian dan generalisasi dari konsep.

Sedangkan problem based learning merupakan model pembelajaran yang diawai dengan pemberian masalah terhadap siswa sehingga siswa dituntut untuk aktif dalam proses pembelajaran (Cahyaningsih, 2016: 104). Pemecahan masaah dengan berpikir kreatif memiliki hubungan karena berpikir kreatif sebuah proses yang digunakan untuk menemukan ide baru yang menghubungkan ide sebelumnya, problem based learning dilakukan untuk membangkitkan berpikir kreatif daam situasi pemecahan masalah (Hasmiati, 2016). Pembelajaran berbasis masalah ialah sebuah kegiatan dengan cara memunculkan serta menggunakan permasalahan untuk dijadikan bahan berpikir siswa untuk dipecahkan permasalahan tersebut dan memperoleh pengetahuan dari kegiatan itu (Kiswanto, 2017).

\section{METODE}

Penelitian ini menggunakan metode eksperimen dengan teknik kuasi eksperimen. Kuasi eksperimen dengan subjek penelitian dikelompokkan secara purposive sampling. Populasi terjangkau dalam penelitian yaitu siswa SMK swasta di Kabupaten Tangerang yang meliputi: 1) SMK Bina Mandiri; dan 2) SMK Bina Karya

Ukuran sampel penelitian sebanyak 80 siswa dengan rincian masing-masing kelompok 40 siswa kelas eksperimen dan 40 siswa kelas kontrol. Dalam penelitian ini digunakan dua jenis instrumen, (1) tes berpikir kreatif, dan (2) tes kemampuan pemecahan masalah matematika. Kedua tes tersebut dalam penelitian ini masing-masing digunakan dengan kepentingan berbeda. Desain penelitian yang digunakan menggunakan Posttest-Only-Design dengan multivariate analysis of variance (MANOVA).

Tabel 1. Desain Penelitian

\begin{tabular}{cc}
\hline & $(\mathrm{A})$ \\
\hline$\left(\mathrm{A}_{1}\right)$ & $\left(\mathrm{A}_{2}\right)$ \\
$\left(\mathrm{Y}_{1} \mathrm{Y}_{2}\right)$ & $\left(\mathrm{Y}_{1} \mathrm{Y}_{2}\right)$ \\
\hline
\end{tabular}

Sumber : Data penelitian yang diolah 
Keterangan :

A : Model Pembelajaran

$\mathrm{A}_{1}$ : Model Pembelajaran Discovey Learning

$\mathrm{A}_{2}$ : Model Pembelajaran Problem Based Learning

$\mathrm{Y}_{1}$ : Berpikir Kreatif

$\mathrm{Y}_{2}$ : Kemampuan Pemecahan Masalah Matematika

\section{HASIL}

Hasi penelitian terhadap siswa SMK swasta kelas XI Kabupaten Tangerang, berupa berpikir kreatif $\left(\mathrm{Y}_{1}\right)$ dan kemampuan pemecahan masalah matematika $\left(\mathrm{Y}_{2}\right)$ yaitu dengan perlakuan model pembelajaran discovery learning $\left(\mathrm{A}_{1}\right)$ dan problem based learning $\left(\mathrm{A}_{2}\right)$

Tabel 2. Hasil Perhitungan Skor

\begin{tabular}{llllllll}
\hline & \multicolumn{1}{c}{ A1 } & & \multicolumn{3}{c}{ A2 } \\
\hline & Y1 & & Y2 & & Y1 & & Y \\
$\mathrm{n}$ & $=40$ & $\mathrm{n}$ & $=40$ & $\mathrm{n}$ & $=40$ & $\mathrm{n}$ & $=40$ \\
$\overline{\mathrm{X}}$ & $=35,87$ & & $=15,83$ & $\overline{\mathrm{X}}$ & $=33,82$ & & $=13,90$ \\
& $=1,964$ & $\mathrm{X}$ & $=1,430$ & $\mathrm{X}$ & $=2,395$ & $\overline{\mathrm{X}}$ & $=1,614$ \\
\hline
\end{tabular}

Sumber : Data penelitian yang diolah

Rekapitulas uji normalitas yang dilakukan pada empat data kelompok yaitu (1) berpikir kreatif ( $\left.\mathrm{Y}_{1}\right)$ terhadap kelompok discovery learning $\left(\mathrm{A}_{1}\right)$; (2) berpikir kreatif $\left(\mathrm{Y}_{1}\right)$ terhadap kelompok problem based learning $\left(\mathrm{A}_{2}\right)$; (3) kemampuan pemecahan masalah matematika $\left(\mathrm{Y}_{2}\right)$ terhadap kelompok discovery learning $\left(\mathrm{A}_{1}\right)$; dan (4) kemampuan pemecahan masalah matematika $\left(\mathrm{Y}_{2}\right)$ terhadap kelompok probem based learning $\left(\mathrm{A}_{2}\right)$.

Pengujian prasyarat untuk mengetahui sampel berasal dari populasi yang berdistribusi normal dilakukan dengan bantuan program SPSS menggunakan uji normalitas. Pengujian normalitas data penelitian yaitu: 1) Berpikir kreatif ( $\left.\mathrm{Y}_{1}\right)$ pada kelompok discovery learning $\left(\mathrm{A}_{1}\right)$; 2) Berpikir kreatif $\left(\mathrm{Y}_{1}\right)$ pada kelompok problem based learning $\left(\mathrm{A}_{2}\right)$; 3) Kemampuan pemecahan masalah matematika $\left(\mathrm{Y}_{2}\right)$ pada kelompok discovery learning $\left(\mathrm{A}_{1}\right)$; dan 4) Kemampuan Pemecahan masalah matematika $\left(\mathrm{Y}_{2}\right)$ pada kelompok problem based learning $\left(\mathrm{A}_{2}\right)$

Tabel 3. Hasi Perhitungan Uji Normalitas Empat Kelompok Data

\begin{tabular}{cccccc}
\hline & & $\mathbf{Y}_{\mathbf{1}} \mathbf{A}_{\mathbf{1}}$ & $\mathbf{Y}_{\mathbf{1}} \mathbf{A}_{\mathbf{2}}$ & $\mathbf{Y}_{\mathbf{2}} \mathbf{A}_{\mathbf{1}}$ & $\mathbf{Y}_{\mathbf{2}} \mathbf{A}_{\mathbf{2}}$ \\
\hline $\mathrm{N}$ & & 40 & 40 & 40 & 40 \\
Normal Parameters $^{a}$ & Mean & 35.88 & 34.08 & 15.80 & 13.92 \\
& Std. Deviation & 1.964 & 2.546 & 1.454 & 1.607 \\
Most Extreme Differences & Absolute & .150 & .167 & .155 & .169 \\
& Positive & .108 & .117 & .109 & .131 \\
& Negative & -.150 & -.167 & -.155 & -.169 \\
Kolmogorov-Smirnov Z & & .951 & 1.055 & .979 & 1.066 \\
Asymp. Sig. (2-tailed) & & .326 & .216 & .294 & .206 \\
\hline
\end{tabular}

Sumber : Data penelitian yang diolah 
Diperoleh nilai Kolmogorov-Smirnov $Z=0,951$ dan p-value (Asympg.Sig) $=0,326>0,05$ dapat dikatakan $\mathrm{Y}_{1}$ pada $\mathrm{A}_{1}$ berdistribusi normal. Kolmogorov-Smirnov $Z=1,055$ dan $p$-value $($ Asympg.Sig) $=$ $0,216>0,05$ dapat dikatakan $\mathrm{Y}_{1}$ pada $\mathrm{A}_{2}$ berdistribusi normal. Kolmogorov-Smirnov $Z=0,979$ dan $p$-value (Asympg.Sig) $=0,294>0,05$ dapat dikatakan $\mathrm{Y}_{2}$ pada $\mathrm{A}_{1}$ berdistribusi normal. Kolmogorov-Smirnov $\mathrm{Z}=$ 1,066 dan $p$-value (Asympg.Sig) = 0,206 > 0,05 dapat dikatakan bahwa $\mathrm{Y}_{2}$ pada $\mathrm{A}_{2}$ berdistribusi normal. Dari hasil pengujian semua data kelompok berdistribusi normal. Karena semua memiliki nilai $p$-value (Asympg.Sig) lebih dari 0,05 dan dapat dikatakan bahwa data dalam penelitian ini berdistibusi normal

Empat kelompok data dinyatakan memiliki distribusi normal. Hal tersebut menunjukkan bahwa telah terpenuhi prasyarat uji F. Uji homogenitas dengan pengujian homogenitas antara matrik varian kovarian dan pengujian homogenitas antara varian kelompok data.

Homogenitas matrik varian-kovarian pengujiannya dilakukan dengan statistika Box's test of equality of covariate matrices.

Tabel 4. Hasil Perhitungan Homogenitas Matrik Varian - Kovarian

\begin{tabular}{lc}
\hline Box's M & 2,444 \\
$\mathrm{~F}$ & 0,797 \\
$\mathrm{df}_{1}$ & 3 \\
$\mathrm{df}_{2}$ & 1075,000 \\
Sig. & 0,506 \\
\hline a. Design: Intercept $+\mathrm{A}$ &
\end{tabular}

Hasil perhitungan menunjukkan bahwa nilai Box's $\mathrm{M}=2,444$ dan $\mathrm{F}=0,797$ dengan $p=v a l u e$ (sig) sbesar 0,506 maka dapat dinyatakan bahwa matrik varian kovarian antara kelompok $\mathrm{A}_{1}$ dan $\mathrm{A}_{2}$ homogen.

Tabel 5. Hasil Perhitungan Homogenitas Varian dengan Uji Levene

\begin{tabular}{|c|c|c|c|c|}
\hline & F & $\mathrm{df}_{1}$ & $\mathrm{df}_{2}$ & Sig. \\
\hline$Y_{1}$ & 2.728 & 1 & 78 & .103 \\
\hline$Y_{2}$ & .098 & 1 & 78 & .756 \\
\hline
\end{tabular}

Untuk pengujian homogenitas antara varian data kelompok dengan uji levene seperti pada Tabel 5. Untuk mengetahui homogenitas berpikir kreatif dan kemampuan pemecahan masalah matematika terhadap discovery learning dan problem based learning. Untuk baris $\mathrm{Y}_{1}$ nilai $\mathrm{F}=2,728$ dan sig $=0,103>0,05$; dapat dikatakan untuk varian data $\mathrm{Y}_{1}$ dengan kelompok $A_{1}$ dengan $A_{2}$ homogen. Untuk bari $\mathrm{Y}_{2}$ Dan nilai $\mathrm{F}=$ 2,728 dan sig $=0,103>0,05$; dapat dikatakan untuk varian data $\mathrm{Y}_{2}$ dengan kelompok $A_{1}$ dengan $A_{2}$ homogen. Dari hasil tersebut dapat dikatakan bahwa berpikir kreatif dan kemampuan pemecahan masalah matematika dengan kelompok model discovery learning dan problem based learning homogen.

Penelitian ini dalam uji hipotesis dengan bantuan program SPSS menggunakan teknik analisis Manova (Multivariate of varians) 
Tabel 6. Tes Multivariat

\begin{tabular}{|c|c|c|c|c|c|c|c|}
\hline Effect & & Value & $\mathrm{F}$ & $\begin{array}{c}\text { Hypothesis } \\
d f\end{array}$ & Error $d f$ & Sig. & $\begin{array}{c}\text { Partial Eta } \\
\text { Squared }\end{array}$ \\
\hline \multirow[t]{4}{*}{ Intercept } & Pillai's Trace & .997 & $1.408 \mathrm{E} 4^{\mathrm{a}}$ & 2.000 & 77.000 & .000 & .997 \\
\hline & Wilks' Lambda & .003 & $1.408 \mathrm{E} 4^{\mathrm{a}}$ & 2.000 & 77.000 & .000 & .997 \\
\hline & Hotelling's Trace & 365.615 & $1.408 \mathrm{E} 4^{\mathrm{a}}$ & 2.000 & 77.000 & .000 & .997 \\
\hline & Roy's Largest Root & 365.615 & $1.408 \mathrm{E} 4^{\mathrm{a}}$ & 2.000 & 77.000 & .000 & .997 \\
\hline \multirow[t]{4}{*}{$M B$} & Pillai's Trace & .314 & $17.639^{\mathrm{a}}$ & 2.000 & 77.000 & .000 & .314 \\
\hline & Wilks' Lambda & .686 & $17.639^{a}$ & 2.000 & 77.000 & .000 & .314 \\
\hline & Hotelling's Trace & .458 & $17.639^{\mathrm{a}}$ & 2.000 & 77.000 & .000 & .314 \\
\hline & Roy's Largest Root & .458 & $17.639^{\mathrm{a}}$ & 2.000 & 77.000 & .000 & .314 \\
\hline
\end{tabular}

Tabel 7. Uji Efek Antar Subjek

\begin{tabular}{|c|c|c|c|c|c|c|c|}
\hline Source & $\begin{array}{l}\text { Dependent } \\
\text { Variable }\end{array}$ & $\begin{array}{c}\text { Type III Sum of } \\
\text { Squares }\end{array}$ & $d f$ & $\begin{array}{l}\text { Mean } \\
\text { Square }\end{array}$ & $F$ & Sig & $\begin{array}{c}\text { Partial Eta } \\
\text { Squared }\end{array}$ \\
\hline \multirow{2}{*}{$\begin{array}{l}\text { Corrected } \\
\text { Model }\end{array}$} & $\mathrm{Y}_{1}$ & $84.050^{\mathrm{a}}$ & 1 & 84.050 & 17.522 & .000 & .183 \\
\hline & $\mathrm{Y}_{2}$ & $74.113^{\mathrm{b}}$ & 1 & 74.113 & 31.872 & .000 & .290 \\
\hline \multirow[t]{2}{*}{ Intercept } & $\mathrm{Y}_{1}$ & 97161.800 & 1 & 97161.800 & $2.026 \mathrm{E} 4$ & .000 & .996 \\
\hline & $\mathrm{Y}_{2}$ & 17671.513 & 1 & 17671.513 & $7.600 \mathrm{E} 3$ & .000 & .990 \\
\hline \multirow[t]{2}{*}{$M B$} & $\mathrm{Y}_{1}$ & 84.050 & 1 & 84.050 & 17.522 & .000 & .183 \\
\hline & $\mathrm{Y}_{2}$ & 74.113 & 1 & 74.113 & 31.872 & .000 & .290 \\
\hline \multirow[t]{2}{*}{ Error } & $\mathrm{Y}_{1}$ & 374.150 & 78 & 4.797 & & & \\
\hline & $\mathrm{Y}_{2}$ & 181.375 & 78 & 2.325 & & & \\
\hline \multirow[t]{2}{*}{ Total } & $\mathrm{Y}_{1}$ & 97620.000 & 80 & & & & \\
\hline & $\mathrm{Y}_{2}$ & 17927.000 & 80 & & & & \\
\hline \multirow{2}{*}{$\begin{array}{l}\text { Corrected } \\
\text { Total }\end{array}$} & $Y_{1}$ & 458.200 & 79 & & & & \\
\hline & $\mathrm{Y}_{2}$ & 255.488 & 79 & & & & \\
\hline
\end{tabular}

Hipotesis penelitian $\left(\mathrm{H}_{1}\right)$ pertama yaitu "terdapat pengaruh A terhadap $\mathrm{Y}_{1}$ dan $\mathrm{Y}_{2}$ ". Hal ini ditunjukkan pada Tabel 6. Multivariate Test pada uji statistika yaitu nilai $\mathrm{F}=17,639$ dengan nilai sig 0,000 kurang dari 0,05. Hal ini dapat dikatakan bahwa signifikan terdapat perbedaan nilai matrik data berpikir kreatif dan kemampuan pemecahan masalah antara kelompok $A_{1}$ dengan kelompok $A_{2}$. Dengan demikian dapat disimpulkan bahwa secara signifikan terdapat pengaruh model pembelajaran discovery learning dan problem based learning terhadap berpikir kreatif dan kemampuan pemecahan matematika. Dalam hal ini data berpikir kreatif dan kemampuan pemecahan masalah matematika pada kelompok belajar menggunakan discovery learning lebih tinggi daripada kelompok belajar dengan problem based learning.

Hipotesis penelitian $\left(\mathrm{H}_{1}\right)$ kedua yaitu "terdapat pengaruh A terhadap $\mathrm{Y}_{1}$ ”. Hal ini ditunjukkan pada Tabel 7. Multivariate Test pada uji statistika yaitu nilai $\mathrm{F}=17,522$ dengan dengan nilai sig 0,000 kurang dari 0,05. Hal ini dapat dikatakan bahwa secara signifikan terdapat perbedaan nilai matrik data berpikir kreatif antara kelompok $\mathrm{A}_{1}$ dengan kelompok $\mathrm{A}_{2}$. Dengan demikian dapat disimpulkan bahwa secara signifikan terdapat pengaruh model discovery learning dan problem based learning terhadap berpikir kreatif.

Hipotesis penelitian $\left(\mathrm{H}_{1}\right)$ ketiga yaitu " terdapat pengaruh A terhadap $\mathrm{Y}_{2}$ ”. Hal ini ditunjukkan pada Tabel 7. Multivariate Test pada uji statistika yaitu nilai $\mathrm{F}=31,872$ dengan nilai sig 0,000 kurang dari 0,05. 
Hal ini dapat dikatakan bahwa secara signifikan terdapat perbedaan nilai matrik data berpikir kreatif antara kelompok $\mathrm{A}_{1}$ dengan kelompok $\mathrm{A}_{2}$. Dengan demikian model pembeajaran discovery learning dan problem based learning memiliki pengaruh terhadap kemampuan pemecahan masalah matematika.

\section{PEMBAHASAN}

Hasil analisis inferensial secara multivariat menyimpulkan bahwa terdapat pengaruh model pembelajaran discovery learning dan problem based learning terhadap berpikir kreatif dan kemampuan pemecahan masaah matematika. Hal ini sejalan dengan penelitian Sari (2017:776) dengan model pembelajaran discovery learning dapat meningkatkan keaktifan siswa dan mengembangkan pola pikir sehingga dapat dikatakan berpikir kreatif siswa meningkat karena siswa dapat menemukan konsep dalam pembelajaran dan mengekspresikan temuannya. Dan model pembelajaran probem based learning memiliki tahapan orientasi, organisasi, analisis dan evaluasi yang membantu siswa untuk mencari jawaban sendiri sesuai dengan permasalahan yang diberikan oleh guru, sehingga kemampuan pemecahan masalah siswa dapat meningkat dengan semakin meningkatkannya berpikir kreatis siswa dalam mencari jawaban dari setiap permasalahan yang diberikan (Abdurozak, 2016, 872).

Hasil analisis inferensial secara univariat menyimpulkan bahwa pertama terdapat pengaruh model pembelajaran discovery learning dan problem based learning terhadap berpikir kreatif. Sabri (2005:79) mengatakan bahwa faktor yang menyebabkan kondisi siswa belajar di sekolah faktor tersebut biasanya berasal faktor internal dan eksternal siswa. Pengaruh yang ada di kehidupan siswa dalam sehari-hari dalam ruang lingkup keluarga, teman dan masyarakat merupakan faktor eksternal yang dapat mempengaruhi adanya perbedaan belajar pada setiap siswa. Untuk mengatasi kondisi tersebut guru dapat memberikan model belajar yang tepat. Dengan model belajar yang tepat akan tercapai tujuan belajar yaitu hasil belajar yang memuaskan. Kedua, terdapat pengaruh model pembelajaran discovery learning dan problem based learning. Peranan matematika dalam upaya Peranan matematika dalam upaya peningkatan sumber daya manusia salah satu pendukungnya adalah matematika karena dalam proses pembelajaran matematika dapat memberikan pengalaman kepada siswa untuk dapat mengalami dan melihat kegunaan matematika dalam kehidupan nyata di keseharian mereka. Oleh karenanya, berpikir kreatif dan kemampuan pemecahan masalah diharapkan dapat menyelesaikan permasalahan kehidupan sehari-hari menggunakan konsepkonsep matematika yang dipelajari. Siswa yang memiliki kemampuan pemecahan masalah akan mampu membuat implikasi dari permasalahan dalam kehidupan sehari-hari yang kompleks, berpikir sistematik, taktis dan praktis.

Model pembelajaran discovery learning dan probem based learning dibutuhkan siswa untuk meningkatkan berpikir kreatif serta permasalahan yang ada dalam matematika. Matematika merupakan mata pelajaran yang diharuskan dapat berpikir secara logis. Setiap masalah atau soal yang diberikan dengan bervariasi maka soal memiliki tingkat keragaman bervariasi pula,mulai dari mudah, sedang ke tinggi, model pembelajaran yang dapat digunakan dengan penerapan model pembelajaran discovery learning dan problem based learning.

Di masa pandemi covid-19 banyak guru dan siswa mengalami kesulitan dalam proses pembelajaran. Salah satu alternatif yang dapat digunakan guru dalam mengajar yaitu model pembelajaran discovery learning karena siswa belajar memahami konsep, arti dan hubungan melalui proses intuitif sampai akhirnya menemukan kesimpulan (Susmiati, 2020: 211). Discovery learning membuat siswa terlibat terutama penggunaan proses mentalnya dalam menemukan konsep dan prinsip yang menyebabkan siswa menjadi berpikir kreatif. 


\section{SIMPULAN}

Berdasarkan hasil penelitian maka dapat dikatakan bahwa terdapat pengaruh model pembelajaran discovery learning dan problem based learning terhadap berpikir kreatif dan kemampuan pemecahan masalah matematika siswa. Fenomena ini menunjukkan bahwa untuk meningkatkan berpikir kreatif dan kemampuan pemecahan masalah matematika dapat dilakukan melalui model pembelajaran discovery learning dan problem based learning. Sehubungan dengan hal di atas maka para guru hendaknya menerapkan model pembelajaran dalam pembelajaran matematika di sekolah. Para guru matematika harus dihimbau dan difasilitasi untuk dapat menerapkan model pembelajaran discovery learning dan problem based learning. Disarankan bagi guru matematika untuk menerapkan model pembelajaran discovery learning dan problem based learning pada pokok bahasan lainya. Untuk pembagian kelompok belajar disarankan pada setiap kelompok didampingi oleh siswa yang memiliki kemampuan matematika yang relatif tinggi. Penelitian replikatif penerapan model pembelajaran discovery learning dan problem based learning untuk meningkatkan kompetensi lainnya dan adanya penelitian lanjutan sebagai salah satu upaya peningkatan berpikir kreatif dan kemampuan pemecahan masalah matematika dengan menggunakan model pembelajaran lainnya yang mempengaruhi variabel dependen (terikat).

\section{DAFTAR RUJUKAN}

Abidin, Y. (2014). Desain Sistem Pembelajaran dalam Konteks Kurikulum 2013. Bandung: PT Refika Aditama.

Abdurrozak, R. (2016). Pengaruh Model Problem Based Learning Terhdap Kemampuan Berpikir Kreatif Siswa. Jurnal Pena Ilmiah, 1(1), 871-880. https://doi.org/10.23819/pi.v1i1.3580

Andriani, A. (2016). Peningkatan Kemampuan Pemecahan Masalah Matematik Mahasiswa FMIPA Pendidikan Matematika Melalui Pembelajaran Improve. Jurnal Tarbiyah, 23 (1), 83-100.

Cahyaningsih, U. (2016). Pengaruh Penggunaan Probem Based Learning Terhadap Karakter Kreatif dan Berpikir Kritis Dalam Pembelajaran Matematika. Jurnal Pendidikan Karakter. https://doi.org/10.21831/jpk.v0i1.10736.

Hasmiati. (2016). Penerapan Model Probem Based Learning (PBL) dalam Meningkatkan Kemampuan Berpikir Kreatif dan Hasil Belajar Siswa. Prosiding Seminar Nasional, 257-262.

Hosnan, M. (2014). Pendekatan Saintifik dan Kontekstual dalam Pembelajaran Abad 21. Bogor: Ghalia Indonesia.

Kiswanto, W. (2017). Implementasi Model Problem Based Learning Untuk Meningkatkan Kemampuan Berpikir Kritis dan Berpikir Kreatif Matematik Siswa SMA. Jurnal PME, 7(2), 137-154. DOI: 10.5035/pjme.v7i2.2717

Maimunah., Purwanto., Sa'dijah, C., \& Sisworo. (2016). Penerapan Model Pembelajaran Matematika Melalui Pemecahan Masalah untuk Meningkatkan Penalaran Matematis Siswa Kelas X-A SMA AL-Musilum. Jurnal Review Pembelajaran Matematika, 1(1), 17-30.

Marantika, A., Handayani, T., \& Putri, A. (2015). Pengaruh Metode Discovery Learning Terhadap Kemampuan Pemecahan Masalah Matematika Siswa Pada Pembelajaran Matematika di SMP Pelita Palembang. Jurnal Pendidikan Matematika RAFA, 1(2), 161-183.

Murtafiah. (2017). Deskripsi Kemampuan Pemecahan Masalah Matematika Ditinjau dari Gaya Kognitif Mahasiswa Pendidikan Matematika Universitas Sulawesi Barat. Jurnal Pendidikan MIPA, 7(1), $48-52$.

Nafisa, D. (2019). Mode Pembeajaran Discovery Learning Berbantuan Multimedia Untuk Meningkatkan Kemampuan Berpikir Kritis Siswa. PRISMA, Prosiding Seminar Nasional Matematika, 854-861. 
Orton, A. \& Frobisher, L. (2009). Insights Into Teaching Mathematics. (London: Continuum). Ebook. https://books.google.com/books?isbn=0826477488.

Prasetyo, H. \& Suhendri, H. (2016). Pengaruh Metode Pembelajaran Brain Based Learning (BBL) Terhadap Kemampuan Berpikir Kreatif Matematis Peserta Didik. Prosiding Seminar Nasional Pendidikan Matematika 2016

Sari, A. D. (2016). Pengaruh Penerapan Model Pembelajaran Kooperatif Tipe Think Pair Share (TPS) Terhadap Kemampuan Berpikir Kreatif Matematika Siswa. Prosiding Seminar Nasional Pendidikan Matematika 2016

Sari, F. A. (2017). Pengaruh Discovery Learning Terhadap Kemampuan Pemecahan Masalah Matematis Siswa. Jurnal Pendidikan Matematika Unila, 5(7).

Susmiati, E. (2020). Meningkatkan Motivasi Belajar Bahasa Indonesia Melalui Penerapan Model Discovery Learning dan Media Video Dalam Kondisi Pandemi Covid-19 bagi Siswa SMPN 2 Gangga. Jurnal Paedagogy, 7(3). https://doi.org/10.33394/jp.v7i3.2732 
120 Ferawati \& Suhendri

JKPM (Jurnal Kajian Pendidikan Matematika) Vol.6, No.1 (2020) 